\title{
Effect of Positive Workplace Gossip on Employee Silence: Psychological Safety as Mediator and Promotion-Focused as Moderator
}

\author{
Ganli Liao ${ }^{1}$, Qianqiu Wang ${ }^{1}$ and $\mathrm{Yi} \mathrm{Li}^{2, *}$ \\ ${ }^{1}$ School of Economics and Management, Beijing Information Science and Technology University, Beijing, 100092, China \\ ${ }^{2}$ Development and Planning Department, Capital Normal University, Beijing, 100044, China \\ *Corresponding Author: Yi Li. Email: 6387@cnu.edu.cn
}

Received: 25 May 2021 Accepted: 30 June 2021

\begin{abstract}
The development of electronic information technology has made workplace gossip more ubiquitous. As a part of interpersonal communication on informal occasions, positive workplace gossip affects individuals' mood, cognition, and behaviors. In light of this and based on the Social Interdependence Theory, the study proposed that positive workplace gossip has a negative effect on employee silence, and psychological safety mediates this relationship. In addition, the promotion-focused moderates the relationship between psychological safety and employee silence. Based on a two-wave sampling design from 311 innovative enterprises employees, the results of Structural Equation Model by AMOS 22.0 and Mplus 7.0 supported all the hypotheses. Results revealed that positive workplace gossip can decrease the employee silence through the mediating role of psychological safety and moderating role of promotion-focused. These findings provided theoretical implications and practical suggestions for enterprise managers to create positive communication climate to reduce employee silence.
\end{abstract}

\section{KEYWORDS}

Positive workplace gossip; employee silence; psychological safety; promotion-focused

\section{Introduction}

With the development of society and progress of science and technology, electronic information technology has enabled employees to exchange all kinds of information in the workplace. Various APPs like Wechat, Tecent QQ and Tik Tok have made gossip behaviors more common in the workplace [1]. Subsequently, the research on workplace gossip has gradually become popular [2,3]. According to Foster [4], gossip occurs in a relaxed and comfortable environment and involves gossip senders, gossip recipients, and gossip targets. Gossip senders and recipients spread the private information about the currently absent gossip targets. Besides, such information is evaluative, positive or negative [5]. A study proposed by Lee et al. [6] has developed a multilevel process model of gossip sender and receiver. Their findings revealed that the motivation of gossip senders may be perceived as self-serving, relational, or prosocial.

Kurland et al. [7], and other scholars established a conceptual model of workplace gossip to delve into the topic and held that workplace gossip belongs to social gossip and is a special form of informal communication that is common and inevitable in organizations [8]. Accordingly, the negative and positive impact of workplace gossip has been widely discussed. In terms of negative impact, workplace 
gossip damages the reputation of others and an organization $[9,10]$. This is especially true if the gossip target receives the negative comments on him/her, which damages individuals' self-esteem and exacerbates intragroup conflicts [11]. In such a case, individuals tend to reduce voice behaviors [12], which further impairs their job performance and stimulates resignation [13]. However, according to some scholars, either positive or negative gossip can constrain individual behaviors, which is conducive to the maintenance of social group norms and the establishment of organizational management mechanisms, thus encouraging organizational citizenship behaviors among individuals and reducing workplace deviant behaviors [13,14]. In this context, whether employees can reduce their silence behaviors when they make positive comments on other members of the organization? As literature showed, employee silence was firstly proposed based on the concept of organizational silence. Morrison et al. [15] held that organizational silence occurs when members of an organization withhold their ideas about critical issues of organizational development. Afterwards, some scholars extended the concept of organizational silence to the individual level and defined employee silence as remaining silent, being unwilling to share their ideas or further concealing key information when they find out the problems of the enterprise or the ability of the enterprise to improve its status quo [16,17]. Employee silence prevent them from providing constructive suggestions for the organization, which has dragged down organizational development and attracted wide attention of scholars $[18,19]$. However, the research on the influence of positive workplace gossip on silence behaviors is insufficient.

Previous literature showed that researchers explored the impact of workplace gossip according to theories such as Self-Verification, Social Learning, and Social Comparison [20-22]. In this study, Social Independent Theory developed by Morton et al. $[23,24]$ was used to illustrated the mechanism between positive workplace gossip and employee silence. In fact, individuals' positive evaluation of superiors in the workplace encourages them to form their positive dependence on the organization. And this dependence helps to foster organizational commitment, which in turn reduces employee silence. Thus, based on the Social Independent Theory, this study also introduced the conception of psychological safety [25] and promotion-focused [26] to explore the relationship between positive workplace gossip and employee silence.

\section{Theory and Hypotheses}

\subsection{Positive Workplace Gossip and Employee Silence}

Based on the dissemination of workplace gossip, it can be divided into negative workplace gossip and positive workplace gossip. Negative workplace gossip means the discussions about someone's deviant behavior, unethical behavior, theft and job burnout in the workplace. Positive workplace gossip refers to the praise and recognition of others' competence, job performance, personality, or charisma [27,28]. Researchers explored the impact of workplace gossip according to different theories. However, few studies have been conducted on positive workplace gossip. These studies focused on its positive impact including voice behaviors of gossip targets and quality of leaders-member exchanges [1], as well as its negative influence like gossip receiver' anxiety and workplace rejection [29].

Employee silence occur when individual choose to withhold their ideas or suggestions without helping the organization improve even when they can solve problems by using their own experience and knowledge [30]. However, the phenomenon that employees cannot express their opinions for they know nothing about the problems cannot be regarded as employee silence [31]. In this paper, employee silence was measured by acquiescent silence, defensive silence, and indifferent silence based on the study carried out by Zheng on employees in Chinese enterprises [32]. Acquiescent silence refers to the passive compliance of employees who deliberately conceal their ideas because they feel unable to change the status quo of the organization or know that their ideas are unlikely to be adopted by the organization. Defensive silence refers to employees' behavior of keeping silent in order to maintain a harmonious interpersonal relationship for 
self-protection, fearing that their thoughts will damage the interpersonal relationship. Indifferent silence refers to individuals' negative coping as they cannot think from the perspective of the organization due to less belonging to and emotional dependence on the organization.

According to the Social Independent Theory, individuals' positive evaluation of superiors in the workplace encourages them to form their positive dependence on the organization $[23,24]$. Such positive dependence helps individuals and leaders establish a high-quality leader-member relationship [33] and therefore employees trust the leaders, which reduces the costs caused by information asymmetry and further promotes the employees and organization to establish cooperative work goals [34]. In such a case, members in the organization will make efforts to achieve the common goals and have positive organizational citizenship behaviors [35]. Therefore, when individuals spot problems of the organization and can change the status quo, they are more motivated to break the silence and "voice" for the organization, thus reducing employees' passive compliant acquiescent silence due to their inability to change the status quo. Meanwhile, individuals' positive evaluation of other members of the organization brings them closer to each other [36], which strengthens organizational cohesion, emotional ties among the members, and individuals' belonging in the organization [37]. Individuals become a part of the organization and regard the cooperative work goals established by themselves and the organization as personal goals. Therefore, positive workplace gossip can effectively inhibit indifferent silence due to any negative attitudes towards the organization. Finally, positive workplace gossip of the organization enhances the positive interaction between members, such as effective communication, as well as mutual respect and support [38,39]. This promotes the harmonious interpersonal relationship among members [5], thus reducing defensive silence. In sum, we proposed that:

H1: Positive workplace gossip is negatively related to employee silence.

\subsection{Mediating Effect of Psychological Safety}

The study of psychological safety was first introduced by Schein et al. [25] into organizational reforms, which was interpreted from the individual and organization level. At the individual level, Kahn believed that psychological safety is a personal characteristic and a manifestation of psychological state and selfperception [40]. Psychologically secured employees will not worry about the negative consequences caused by their self-image or status when presenting themselves. At the organization level, psychological safety was defined as the perception of organizational environment. It means that employees with high psychological safety will perceive organizational support, understand the clear job expectations and express the opinions freely [41]. Take it further, the more freely employees can express their true feelings in the organization, the more organizational psychological safety they will experience. Based on the definition, this study proposed that positive workplace gossip has a positive effect on psychological security, which are explained as follows.

Kahn held that a supportive and trust-based interpersonal relationship is conducive to the improvement of employees' psychological safety [40], and that gossip is good for the cultivation of friendship and the establishment of high-quality interpersonal relationships [27]. If most of the gossip is positive comment or evaluation on the competence and personal charisma of leaders and colleagues rather than negative gossip, employees will find themselves in a harmonious interpersonal relationship and feel psychological safety [42]. At the organization level, organizational psychological safety can be deemed as a secure atmosphere and gossip is conducive to organizational solidarity [14,42]. As a means of information collection for employees, gossip reinforces or changes their working attitudes [43]. When the organization is full of appreciation and other positive gossip about leaders and colleagues, employees will build more trust and confidence in their leaders in a supportive organizational environment and feel more psychological safety [44]. Thus, we proposed that: 
H2: Positive workplace gossip is positively related to psychological safety.

Studies have shown that psychological safety is the key cognitive factor driving voice behaviors $[45,46]$ and inhibiting silence behaviors. Employees tend to take silence behaviors when they feel insecure about voice behaviors or feel scared due to negative expectations [47]. Employees with strong psychological safety can express themselves more freely at work; are more willing to take positive behaviors in the organization [40,48]; take an active role in making innovations [49]; think positively about voice behaviors; and offer more suggestions on organizational improvement. In a psychologically secured environment, employees believe that asking colleagues for help, information, and resources will not annoy them or be punished, which helps reduce deliberate self-protection [50]. In such an organizational climate, when employees discover any problem of the enterprise or they can improve the enterprise's status quo, they are more likely to break the silence and offer suggestions. According to the Social Interdependence Theory, positive interpersonal dependence exists among individuals, and positive workplace gossip helps establish high-quality interpersonal relationships and harmonious organizational atmosphere. In addition, it enhances interpersonal dependence, develops emotional attachment to the organization, and fosters psychological safety [46], which encourages employees to break the silence and speak out freely [51]. Therefore, employees can develop positive perceptions of interpersonal relationships and the organizational atmosphere through positive workplace gossip and thus feel more psychological safety. Positive workplace gossip can reduce deliberate self-protection and defensive silence caused by self-protection, thus enhancing employees' engagement at work. Based on the above findings, a hypothesis was proposed in this paper:

H3: Psychological safety mediates the relationship between positive workplace gossip and employee silence.

\subsection{Moderating Effect of Promotion-Focused}

The Regulatory Focus Theory was first proposed by Higgins [26], which proposed that people would show two tendencies of self-regulation in the process of achieving self-goals: prevention-focused and promotion-focused. People with different regulatory focus would have different reactions in the face of opportunities and risks [52]. Individuals with prevention-focused prefer to avoid losses and failures, whereas individuals with promotion-focused are more likely to pursue positive results [53]. Research showed that promotion-focused can moderate the impact of psychological safety on employee's behaviors [54-56]. For example, the research of Lee et al. [57] found the positive moderating influence of promotion-focused between psychological safety and individual performance. In this study, we proposed that promotion-focused moderates the relationship between psychological safety and employee silence. Based on the conception of promotion-focused, employees with higher promotion-focused will be more positive and open when faced with organizational difficulties. They are more willing to take risks and more sensitive to the positive features of the environment [58]. At this time, they will take a proactive strategy to achieve the goals and reduce their silence [59], which expecting to obtain the organizational support. Thus, we proposed that:

H4: Promotion-focused moderates the relationship between psychological safety and employee silence.

The theoretical model for the study is shown in Fig. 1.

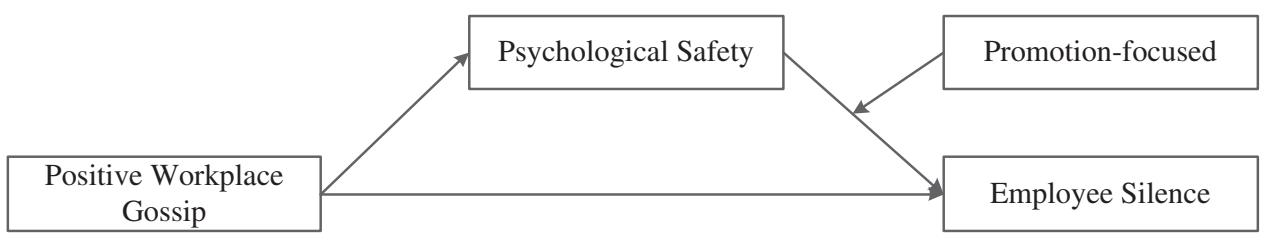

Figure 1: Theoretical model 


\section{Methods}

\subsection{Data Collection and Sample Description}

Samples were collected from four large innovative enterprises in Beijing and Shenzhen, involved technical and development, production and operation, marketing and sales, customer service and functional management jobs. In order to reduce the potential of common-method bias, data were obtained in 2 time stages, respectively. At time T1, we asked employees to rated their positive workplace gossip, psychological safety and reported their demographic information. A total of 430 questionnaires were sent out and 397 were collected, with a response rate of $92.3 \%$. Three months later, at time T2, these 397 employees were asked to complete the focused-promotion and employee silence. And 326 questionnaires were collected with a response rate of $94.7 \%$. After eliminating invalid questionnaires with a deletion rate of over $10 \%$ and a repetition rate of over $90 \%, 311$ valid questionnaires were used for the final analysis.

Of all the employees in the survey, $63.2 \%$ were males and $36.8 \%$ were females. The employees were divided into five age groups: 18-25 (13.5\%), 26-35 (42.7\%), 36-45 (37.3\%), 46-55 (6.5\%), and 56 and above $(0 \%)$. The reason is that the retirement age for Chinese companies is 50 years old for women and 55 years old for men. The sample in this study were collected from innovative enterprises in China, whose employees are generally younger, so employees over 56 years old accounted for $0 \%$ of the research sample. In terms of education level, $12.9 \%$ had a high school education or less, $25.6 \%$ had a college education, $37.1 \%$ had a bachelor's degree and $24.4 \%$ had a master's degree or above. In terms of working years, employees with less than 1 year accounted for $12.5 \%$, those with 1-3 years accounted for $25.8 \%$, those with 3-5 years accounted for $31.2 \%$, those with 5-8 years accounted for $22.6 \%$, and those with more than 8 years accounted for $7.9 \%$.

\subsection{Measures}

All variables in this study were measured from mature scales published in top journals. In order to ensure the reliability and validity of the scale, the standard translation method was adopted.

Positive workplace gossip. At time T1, positive workplace gossip was assessed by Brady with 10 items. This scale was assessed on a Likert-7 scale ( $1=$ "never" and $7=$ "more than once a day"). Sample item is "told colleagues that you respect another colleague". The Cronbach's $\alpha$ for this scale was 0.952 .

Psychological safety. At time T1, this scale was measured with a Likert-5 scale (1 = "strongly disagree" to $5=$ "strongly agree") developed by Zhang. Sample item is "I am not afraid of the disadvantage of expressing my true thoughts". This scale has been widely applied in Chinese studies and has good reliability and validity. In the study, the psychological safety also has shown good reliability with Cronbach's $\alpha$ was 0.852 .

Promotion-focused. At time T2, promotion-focused scale was assessed using a Chinese version developed by Shi et al. [52] It consists of 8 items (e.g., I frequently imagine how I will achieve my hopes and aspirations), and uses Liket- 5 scale ( $1=$ "strongly disagree" to $5=$ "strongly agree"). In this study, Cronbach's $\alpha$ was 0.885 .

Employee silence. Zheng [32] developed the Chinese version of employee silence, which was consist of 12 items with 3 dimensions: acquiescence silence (e.g., "When the leader makes a decision, my opinions are useless"), defensive silence (e.g., "In order to maintain the interpersonal relationship between colleagues, I chose to remain silent about the deficiencies and negligence of others in their work") and indifference silence (e.g., "I do not have a deep relationship with my organization, so there is no need to make suggestions"). At time T2, employee silence was scored on a Likert-5 scale ( $1=$ "strongly disagree" to $5=$ "strongly agree"). It also has shown good reliability with Cronbach's $\alpha$ was 0.914 . 
Controlled variables. Prior research suggests that demographic variables such as age, gender, education level and working years influence employee behavior and judgments [60]. Different ages, gender, and education level of employees may lead to differences in physical ability and energy, which will directly affect the likelihood of spreading workplace gossip [61]. In addition, employees' differences in gender and working years will affect their employee silence [62]. In view of this, gender, ages, education level and working years were controlled in this study.

\subsection{Data Analysis}

In this study, data were analyzed by AMOS22.0 and Mplus 7.0. Firstly, descriptive statistical analysis and correlation analysis were conducted on the samples. Secondly, confirmatory factor analysis was performed using AMOS22.0. Finally, structural equation model was constructed to test the hypothesized model using Mplus 7.0, and Bootstrap analysis was performed to examine the mediating effect of psychological safety using Hayes multiple mediation method [63].

\section{Results}

\subsection{Descriptive Analysis}

The means, standard deviations (SD) and correlation coefficients of all variables in this study are shown in Table 1. The results show that positive workplace gossip was negatively related to employee silence $(\gamma=-0.395, p<0.01)$, and positively related to psychological safety $(\gamma=0.324, p<0.01)$. In addition, psychological safety had a negative relationship with employee silence $(\gamma=-0.294, p<0.01)$. These results provide preliminary evidence to support our hypotheses.

Table 1: The results of descriptive analysis

\begin{tabular}{lllllll}
\hline Variables & Mean & SD & 1 & 2 & 3 & 4 \\
\hline 1. Positive workplace gossip & 3.48 & 1.45 & 1 & & & \\
2. Employee silence & 2.92 & 0.69 & $-0.395^{* *}$ & 1 & & \\
3. Psychological safety & 3.01 & 0.79 & $0.324^{* *}$ & $-0.294^{* *}$ & 1 & \\
4. Promotion-focused & 4.95 & 0.92 & $0.387^{* *}$ & $-0.317^{* *}$ & $0.175^{* *}$ & 1 \\
\hline
\end{tabular}

\subsection{Confirmatory Factor Analysis}

Before hypothesis testing, we conducted confirmatory factor analyses with AMOS 22.0 to validate all multiple-item scales. As showed in Table 2, we first estimated the proposed model with all latent variables (positive workplace gossip, psychological safety, promotion-focused and employee silence) into a model. The four-factor model had a good fit $\left(\chi^{2} / d f=3.00, p<0.001\right.$, CFI $=0.90$, TLI $=0.89$, RMSEA $\left.=0.07\right)$. All the factor loadings were above the suggested threshold of 0.50 and significant at the $p<0.001$ level. It suggested that the scales had acceptable internal validity. Next, we examined the discriminant validity of the full measurement model by contrasting it to eleven alternative models. These alternative models were created to assess the distinctiveness of each variable. For example, three-factor model 1 (combine psychological safety and promotion-focused) was created to assess the distinctiveness of the mediating and moderating variables $\left(\chi^{2} / d f=5.20, p<0.001, \mathrm{CFI}=0.77\right.$, TLI $=0.74$, RMSEA $\left.=0.11\right)$. Two-factor modell (combine positive workplace gossip, psychological safety and promotion-focused) was created to assess the distinctiveness of the independent variable $\left(\chi^{2} / d f=9.43, p<0.01\right.$, CFI $=0.52$, TLI $=0.47$, RMSEA $=0.15)$. One-factor model was tested $\left(\chi^{2} / d f=10.83, p<0.001\right.$, CFI $=0.44$, TLI $=0.38$, RMSEA $=0.17)$. The results were showed in Table 1 . The CFA results demonstrated that the model fit of the alternative models was poorer fit compared to the four factors model. 
Table 2: The results of confirmatory factor analysis

\begin{tabular}{llllllll}
\hline Model & Factors & $\chi^{2}$ & $d f$ & $\chi^{2} / d f$ & CFI & TLI & RMSEA \\
\hline One-factor model & PWG+PS+PF+ES & 2489.70 & 230 & 10.83 & 0.44 & 0.38 & 0.17 \\
Two-factor model 1 & PWG+PS+PF, ES & 2159.62 & 229 & 9.43 & 0.52 & 0.47 & 0.15 \\
Two-factor model 2 & PWG, PS+PF+ES & 1869.34 & 229 & 8.16 & 0.59 & 0.54 & 0.14 \\
Two-factor model 3 & PWG+PF+ES, PS & 1864.27 & 229 & 8.14 & 0.59 & 0.55 & 0.14 \\
Two-factor model 4 & PWG+PS +ES, PF & 1854.94 & 229 & 8.10 & 0.59 & 0.55 & 0.14 \\
Three-factor model 1 & PWG, PS+PF, ES & 1164.87 & 224 & 5.20 & 0.77 & 0.74 & 0.11 \\
Three-factor model 2 & PWG+PS, PF, ES & 974.48 & 224 & 4.35 & 0.82 & 0.79 & 0.10 \\
Three-factor model 3 & PWG+ PF, PS, ES & 956.42 & 224 & 4.27 & 0.83 & 0.78 & 0.09 \\
Three-factor model 4 & PWG+ ES, PF, PS & 943.05 & 224 & 4.21 & 0.83 & 0.78 & 0.09 \\
Three-factor model 5 & PWG, PS +ES, PF & 866.80 & 224 & 3.87 & 0.85 & 0.82 & 0.08 \\
Three-factor model 6 & PWG, PS, PF+ES & 815.33 & 224 & 3.64 & 0.87 & 0.83 & 0.08 \\
Four-factor model & PWG, PS, PF, ES & 661.09 & 220 & 3.00 & 0.90 & 0.89 & 0.07 \\
\hline
\end{tabular}

Note: $\mathrm{PWG}=$ positive workplace gossip; PS = psychological safety; PF = Promotion-focused; ES = Employee Silence. CFI = Comparative Fix Index; TLI $=$ Tucker-Lewis Index; RMSEA $=$ Root Mean Square Error of Approximation

\subsection{Tests of Hypotheses}

Based on the research of Hayes et al., the mediating effect needs to meet the following conditions [63]. Condition (1), the effect of independent variables on mediating variables $\left(a_{i}\right)$ and the effect of mediating variables $\left(b_{i}\right)$ on dependent variables are both significant. Condition (2), the significance of the indirect effect $a_{i}{ }^{*} b_{i}$ was tested and the Bootstraping method ( $=5000$ times) was used to further test whether the confidence interval of $a_{i}{ }^{*} b_{i}$ (at the $95 \%$ level) includes zero.

Based on these, a structural equation model was developed by busing Mplus 7.0 to test the hypotheses. The results are shown in Table 3. In Model 1, after controlling the demographic variables, there was a negative relationship between positive workplace gossip and employee silence $(\beta=-0.464, p<0.001)$. Then, H1 was supported. In Model 2, the coefficient between positive workplace gossip and psychological safety was significant $(\beta=0.464, p<0.001)$, thus, H2 was supported. In Model 3, after entering the demographic variables and positive workplace gossip, the relationship between psychological safety and employee silence was significant $(\beta=-0.162, p<0.001)$. The above results show that the path coefficients of independent variables and mediating variables, as well as mediating variables and dependent variables are significant. The results revealed that the condition (1) was met. Subsequently, the significance of the mediating effect was tested by Bootstrapping method ( $=5000$ times). Result of bootstrap bias-corrected $95 \%$ CIs was $[-0.138,-0.009]$, excluded zero. Then, the condition (2) was met. These results indicated that the indirect effect of positive workplace gossip on employee silence through psychological safety was significant $(\beta=-0.073, p<0.05)$. Thus, $\mathrm{H} 3$ was supported.

H4 proposed that promotion-focused moderates the relationship between psychological safety and employee silence. We conducted Model 4 to test this proposal. As presented in Table 3, after controlling the demographic variables, the interaction of psychological safety and promotion-focused was significant $(\beta=-0.185, p<0.001)$. Therefore, $\mathrm{H} 4$ was supported.

Moreover, according to Aiken et al. [64], we conducted a Simple slope test to analyze the moderating effect of promotion-focused at different level (Mean $\pm 1 \mathrm{SD}$ ). As showed in Fig. 2, psychological safety has a stronger negative effect on employee silence when employee's promotion-focused is at a higher level (Simple slope $\beta=-0.298, p<0.001$ ). Meanwhile, psychological safety has a weaker negative effect when employee's promotion-focused is at a lower level (Simple slope $\beta=-0.271, p<0.001$ ). 
Table 3: The results of structural equation model

\begin{tabular}{lllll}
\hline Variables & $\begin{array}{l}\text { Model 1 } \\
\text { Employee } \\
\text { silence }\end{array}$ & $\begin{array}{l}\text { Model 2 } \\
\text { Psychological } \\
\text { safety }\end{array}$ & $\begin{array}{l}\text { Model 3 } \\
\text { Employee } \\
\text { silence }\end{array}$ & $\begin{array}{l}\text { Model 4 } \\
\text { Employee silence }\end{array}$ \\
\hline Gender & -0.023 & 0.044 & -0.013 & 0.029 \\
Ages & $0.212^{*}$ & -0.057 & $0.172^{*}$ & $0.171^{*}$ \\
Education level & -0.026 & -0.024 & -0.026 & -0.028 \\
Working years & $-0.3 * * *$ & 0.031 & $-0.251^{* * *}$ & $-0.235^{* * *}$ \\
Positive workplace & $-0.464^{* * *}$ & $0.464^{* * *}$ & $-0.431^{* * *}$ & \\
gossip & & & & \\
Psychological safety & & & $-0.162^{* * *}$ & $-0.146^{* *}$ \\
Promotion-focused & & & $-0.264^{* * *}$ \\
Psychological safety $\times$ Promotion-focused & & & $-0.185^{* * *}$ \\
\hline
\end{tabular}

Note: $\mathrm{N}=311,{ }^{*} p<0.05, * * p<0.01, * * * p<0.01$.

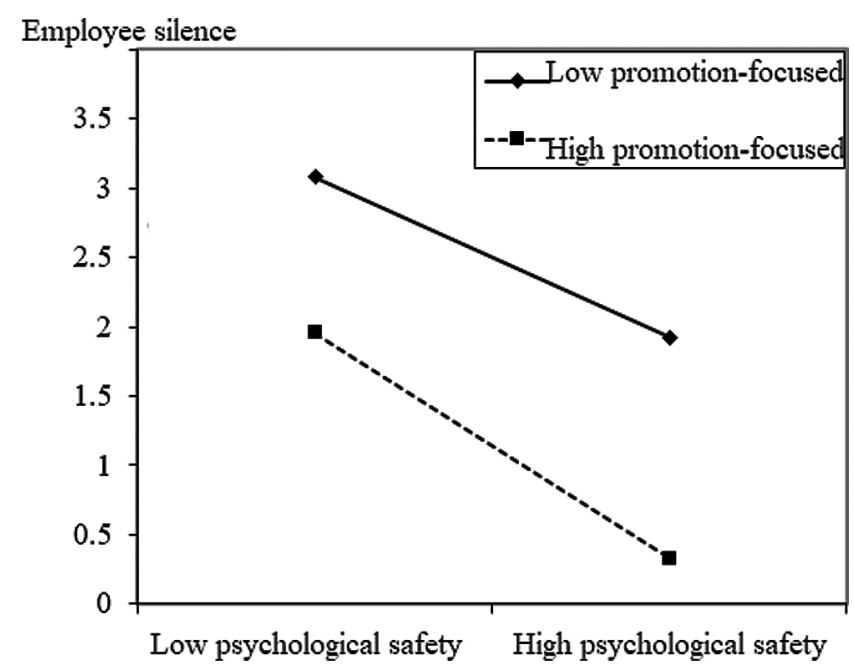

Figure 2: The moderating effect on the relationship between psychological safety and employee silence

\section{Discussion}

The primary purpose of this paper was to investigate how positive workplace gossip influence employees in their behaviors. Drawing from social independent theory, the relationships among positive workplace, employee silence, and intermediating variables like psychological safety and promotionfocused were examined. The theoretical and practical implications were discussed as follows.

\subsection{Theoretical Implications}

It was found through literature review that most scholars focused on the negative impact of negative workplace gossip on gossip targets such as employees' innovative behaviors, service quality and knowledge hiding [65-67]. At present, the studies of the impact on gossip senders are still scarce. Most of them explored the positive influence of positive workplace gossip [5]. The results showed that positive workplace gossip has a negative impact on employee silence, which enriched the empirical research of positive workplace gossip and employee silence. In addition, the relationship between gossip and silence 
was illustrated from the perspective of the social interdependence theory, which enriched the relevant theoretical achievements. Theoretically, individuals' positive evaluation of superiors and their colleagues helps foster the positive dependence on the organization and improve the cohesion of the organization, which encourages members to take positive organizational citizenship behaviors and reduce individual silence. Therefore, this study not only enriched the empirical research on the impact of positive workplace gossip, but also deepened the understanding of the antecedents of employee silence behaviors.

Secondly, this study found the partial mediating effect of psychological safety between positive workplace gossip and employee silence. That is, positive workplace gossip positively related to psychological safety, and psychological safety was negatively related to employee silence. These findings line up with the scholars' results $[18,68,69]$, in which employees who showed a higher level of psychological safety showed less employee silence. A possible explanation for these results might be that when employee sender others' positive workplace gossip like rewards, honors and praise, the senders tend to experience more harmonious interpersonal relationship and high level of psychological safety [42-44]. Accordingly, psychological safety is a vital resource for reducing all kinds of employee silence, whether it can be acquiescence silence, defensive silence or indifference silence.

Thirdly, this research found that promotion-focused moderated the negatively relationship between psychological safety and employee silence, and further deepens the understanding of the process of employee silence. Previous studies have proposed that promotion-focused moderated the effect of psychological safety on employees' voice behavior [70]. This study further explored the moderating effect on employee silence, which provides a new theoretical perspective for exploring the boundary conditions of the relationship between positive workplace gossip and employee silence, but also enriched the theoretical application of regulatory focus theory.

\subsection{Practical Implications}

This paper offered two suggestions for the management. Firstly, it was found that positive workplace gossip has negative impact on employee silence behaviors, which suggests that managers should tighten the management of positive workplace gossip by offering positive guidance of workplace gossip in their daily work, as workplace gossip is inevitable and ubiquitous [71]. What's more, managers should keep their own behaviors upright and set positive examples for employees, thus providing the source of positive workplace gossip. Secondly, the results showed that higher psychological safety of employees can reduce silence behaviors. Therefore, managers need to take measures to enhance the psychological safety of employees. The organization is suggested to establish a fair and just organizational system and adopt reasonable incentive and reward measures as employees have higher psychological safety and take less silence behaviors in this case [46]. In addition, managers should enable employees to feel the support, trust, and psychological safety from the organization and reduce their silence behaviors by facilitating effective communication and cultivating harmonious interpersonal relationships [51].

\subsection{Limitations}

Although the mechanism of positive workplace gossip and employee silence was confirmed by our data, there are still some limitations should be noted. Firstly, based on the social interdependence theory, the negatively influence of positive workplace gossip on employee silence, as well as the mediating effect of psychological safety and moderating effect of promotion-focused were demonstrated in this paper. In the future, other theories (such as the relative deprivation theory, the social contagion theory etc.) and variables (such as prevention-focused, organizational support) may be used to explored this mechanism to expand the depth and breadth of studies. Secondly, all the variables were self-reported. In order to avoid Common Method Bias, future study should collect data from different respondents such as leaders, team members and individuals. Last but not the least, all data samples in this study were sourced from 
innovative enterprises in China. It remains to be studied whether such conclusions can be extended to other countries and cultures.

Funding Statement: This research was funded by the National Natural Science Foundation of China Project (71801017, 72002016, 71901031, 71802025) and Project of Beijing Social Science (No. 18GLC064).

Conflicts of Interest: The authors declare that they have no conflicts of interest to report regarding the present study.

\section{References}

1. Liu, X. Y., Kwan, H. K., Zhang, X. (2020). Introverts maintain creativity: A resource depletion model of negative workplace gossip. Asia Pacific Journal of Management, 37(3), 325-344. DOI 10.1007/s10490-018-9595-7.

2. Ming, K. (2018). Effect of perceived negative workplace gossip on employees' behaviors. Frontiers in Psychology, 9, 1112-1123. DOI 10.3389/fpsyg.2018.01112.

3. Wu, X., Kwan, H. K., Wu, L. Z., Ma, J. (2018). The effect of workplace negative gossip on employee proactive behavior in China: The moderating role of traditionality. Journal of Business Ethics, 148(4), 1-15. DOI 10.1007/ s10551-015-3006-5.

4. Foster, E. K. (2004). Research on gossip: Taxonomy, methods, and future directions. Review of General Psychology, 8(2), 78-99. DOI 10.1037/1089-2680.8.2.78.

5. Kuo, C. C., Wu, C. Y., Lin, C. W. (2018). Supervisor workplace gossip and its impact on employees. Journal of Managerial Psychology, 33(1), 93-105. DOI 10.1108/JMP-04-2017-0159.

6. Lee, S. H., Barnes, C. M. (2021). An attributional process model of workplace gossip. Journal of Applied Psychology, 106(2), 300-316. DOI 10.1037/ap10000504.

7. Kurland, N. B., Pelled, H. L. (2000). Passing the word: Toward a model of gossip and power in the workplace. Academy of Management Review, 25(2), 428-438. DOI 10.2307/259023.

8. Kniffin, K. M., Wilson, D. S. (2010). Evolutionary perspectives on workplace gossip: Why and how gossip can serve groups. Group \& Organization Management an International Journal, 35(2), 150-171. DOI 10.1177/ 1059601109360390.

9. Emler, N. (1994). Gossip, Reputation, and Social Adaptation. In: Goodman, R. F., Ben-Ze'ev, A. (Eds.), Good gossip, pp. 117-138. USA: University Press of Kansas,

10. Farley, S. D. (2019). On the Nature of Gossip, Reputation, and Power Inequality. In: The Oxford handbook on gossip and reputation, pp. 343-358. UK: Oxford University Press, UK.

11. Wu, L. Z., Birtch, T. A., Chiang, F., Zhang, H. (2018). Perceptions of negative workplace gossip: A selfconsistency theory framework. Journal of Management, 44(5), 1873-1898. DOI 10.1177/0149206316632057.

12. Zhu, C., Zhang, F. (2019). Receiving gossip from your leader? Leader gossip and employee voice behavior. Academy of Management Annual Meeting Proceedings, 2019(1), 17220. DOI 10.5465/AMBPP.2019.17220abstract.

13. Wu, J., Balliet, D., van Lange, P. A. (2016). Gossip versus punishment: The efficiency of reputation to promote and maintain cooperation. Scientific Reports, 6(1), 23919. DOI 10.1038/srep23919.

14. Dunbar, R. (2004). Gossip in evolutionary perspective. Review of General Psychology, 8(2), 100-110. DOI 10.1037/1089-2680.8.2.100.

15. Morrison, E. W., Milliken, F. J. (2000). Organizational silence: A barrier to change and development in a pluralistic world. Academy of Management Review, 25(4), 706-725. DOI 10.2307/259200.

16. Brinsfield, C. T. (2013). Employee silence motives: Investigation of dimensionality and development of measures. Journal of Organizational Behavior, 34(5), 671-697. DOI 10.1002/job.1829.

17. Duan, J., Bao, C., Huang, C., Brinsfield, C. T. (2018). Authoritarian leadership and employee silence in China. Journal of Management \& Organization, 24(1), 62-80. DOI 10.1017/jmo.2016.61.

18. Knoll, M., Gtz, M., Adriasola, E., Al-Atwi, A., Zacher, H. (2021). International differences in employee silence motives: Scale validation, prevalence, and relationships with culture characteristics across 33 countries. Journal of Organizational Behavior, 42(5), 619-648. DOI 10.1002/job.2512. 
19. Rai, A., Agarwal, Upasna, A., Cornelius, N., Garavan, T. (2017). Workplace bullying and employee silence: A moderated mediation model of psychological contract violation and workplace friendship. Personnel Review, 47(1), 226-256. DOI 10.1108/PR-03-2017-0071.

20. Brady, D. L., Brown, D. J., Liang, L. H. (2017). Moving beyond assumptions of deviance: The reconceptualization and measurement of workplace gossip. Journal of Applied Psychology, 102(1), 1-25. DOI 10.1037/apl0000164.

21. Roy, F. B., Liqing, Z., Kathleen, D. V. (2004). Gossip as cultural learning. Review of General Psychology, 8(2), 111-121. DOI 10.1037/1089-2680.8.2.111.

22. Sarah, R. W., Peter, S. (2004). A social comparison account of gossip. Review of General Psychology, 8(2), 122 137. DOI 10.1037/1089-2680.8.2.122.

23. Morton, D. (1949a). A theory of co-operation and competition. Human Relations, 2(2), 129-152. DOI 10.1177/ 001872674900200204.

24. Morton, D. (1949b). An experimental study of the effects of co-operation and competition upon group process. Human Relations, 2(3), 199-231. DOI 10.1177/001872674900200301.

25. Schein, E. H., Bennis, W. (1965). Personal and organizational change via group methods. Wiley, New York, USA.

26. Higgins, E. T. (1997). Beyond pleasure and pain. American Psychologist, 52, 1280-1300. DOI 10.1037/0003066X.52.12.1280.

27. Ellwardt, L., Labianca, G., Wittek, R. (2012). Who are the objects of positive and negative gossip at work? A social network perspective on workplace gossip. Social Networks, 34(2), 193-205. DOI 10.1016/j.socnet.2011.11.003.

28. De Gouveia, C. M., van Vuuren, L. J., Crafford, A. (2005). Towards a typology of gossip in the workplace. $S A$ Journal of Human Resource Management, 3(2), 56-68. DOI 10.4102/sajhrm.v3i2.68.

29. Guo, G., Gong, Q., Li, S., Liang, X. (2021). Don't speak ill of others behind their backs: Receivers' ostracism (sender-oriented) reactions to negative workplace gossip. Psychology Research and Behavior Management, 2021(14), 1-16. DOI 10.2147/PRBM.S288961.

30. Pinder, C. C., Harlos, K. P. (2001). Employee silence: Quiescence and acquiescence as responses to perceived injustice. Research in Personnel and Human Resources Management, 3(20), 331-369. DOI 10.1016/S0742-7301(01)20007-3.

31. Linn, V. D., Soon, A., Isabel, C. B. (2003). Conceptualizing employee silence and employee voice as multidimensional constructs. Journal of Management Studies, 40(6), 1359-1392. DOI 10.1111/1467-6486.00384.

32. Zheng, X. T. (2007). A study on the relationship between trust, trust factors and employee silence in employee organization (Doctoral Dissertation). Beijing Jiaotong University.

33. Johnson, D. W., Johnson, R. T. (2005). New developments in social interdependence theory. Genetic, Social, and General Psychology Monographs, 131(4), 285-358. DOI 10.3200/MONO.131.4.285-358.

34. Wan, H. L. (2016). Theories on organizational justice, job satisfaction, leader-member exchange and organizational citizenship behavior. Springer, Singapore.

35. Sun, L. Y., Irene, H. S. C., Randy, K. C., Wen, P. (2013). Outcome favorability in the link between leader-member exchange and organizational citizenship behavior: Procedural fairness climate matters. The Leadership Quarterly, 24(1), 215-226. DOI 10.1016/j.leaqua.2012.10.008.

36. Insko, C. A., Drenan, S., Solomon, M. R., Smith, R., Wade, T. J. (1983). Conformity as a function of the consistency of positive self-evaluation with being liked and being right. Journal of Experimental Social Psychology, 19(4), 341-358. DOI 10.1016/0022-1031(83)90027-6.

37. Weeks, J. W., Heimberg, R. G., Rodebaugh, T. L., Goldin, P. R., Gross, J. J. (2012). Psychometric evaluation of the fear of positive evaluation scale in patients with social anxiety disorder. Psychological Assessment, 24(2), 301312. DOI 10.1037/a0025723.

38. Allen, M. W., Brady, R. M. (1997). Total quality management, organizational commitment, perceived organizational support, and intra-organizational communication. Management Communication Quarterly, 10(3), 316-341. DOI 10.1177/0893318997010003003.

39. Soco, C., Simonovich, S. D., Dillon, D., Bishop-Royse, J., Lattner, C. (2020). Communication, leadership and organizational support facilitate successful transition into practice for nurse practitioners in the emergency department. Journal of the American Association of Nurse Practitioners. DOI 10.1097/JXX.0000000000000500. 
40. Kahn, W. A. (1990). Psychological conditions of personal engagement and disengagement at work. Academy of Management Journal, 33(4), 692-724. DOI 10.5465/256287.

41. Brown, S. P., Leigh, T. W. (1996). A new look at psychological climate and its relationship to job involvement, effort, and performance. Journal of Applied Psychology, 81(4), 358-368. DOI 10.1037/0021-9010.81.4.358.

42. Douglas, R. M., Richard, L. G., Lynn, M. H. (2004). The psychological conditions of meaningfulness, safety and availability and the engagement of the human spirit at work. Journal of Occupational and Organizational Psychology, 77(1), 11-37. DOI 10.1348/096317904322915892.

43. Farley, S. D. (2011). Is gossip power? The inverse relationships between gossip, power, and likability. European Journal of Social Psychology, 41(5), 574-579. DOI 10.1002/ejsp.821.

44. Edmondson, A. C. (2011). Psychological safety, trust, and learning in organizations: A group-level lens. In: Kramer,R. M., Cook, K. S. (Eds.), Trust and distrust in organizations: Dilemmas and approaches, pp. 239272. New York, USA: Russel Sage Foundation.

45. James, R. D., Ethan, R. B. (2007). Leadership behavior and employee voice: Is the door really open? Academy of Management Journal, 50(4), 869-884. DOI 10.5465/AMJ.2007.26279183.

46. Walumbwa, F. O., Schaubroeck, J. (2009). Leader personality traits and employee voice behavior: Mediating roles of ethical leadership and work group psychological safety. Journal of Applied Psychology, 94(5), 1275-1286. DOI 10.1037/a0015848.

47. Kish-Gephart, J. J., Detert, J. R., Treviño, L. K., Edmondson, A. C. (2009). Silenced by fear: The nature, sources, and consequences of fear at work. Research in Organizational Behavior, 29, 163-193. DOI 10.1016/j. riob.2009.07.002.

48. Yoo, J. (2017). Customer power and frontline employee voice behavior: Mediating roles of psychological empowerment. European Journal of Marketing, 51(1), 238-256. DOI 10.1108/EJM-07-2015-0477.

49. Kark, R., Carmeli, A. (2009). Alive and creating: The mediating role of vitality and aliveness in the relationship between psychological safety and creative work involvement. Journal of Organizational Behavior, 30(6), 785804. DOI 10.1002/job.571.

50. Zhang, P. C., Liu, W. X., Liao, J. Q. (2011). The influence mechanism of charismatic leadership on employee creativity: Is psychological security enough? Journal of Management World, 2(10), 94-107. DOI 10.19744/j. cnki.11-1235/f.2011.10.009.

51. Liang, J., Farh, C. I. C., Farh, J. L. (2012). Psychological antecedents of promotive and prohibitive voice: A twowave examination. Academy of Management Journal, 55(1), 71-92. DOI 10.5465/amj.2010.0176.

52. Shi, Q. (2010). A theoretical and empirical study on the influence mechanism of leadership behavior on employees' work attitude (Doctoral Dissertation). Southwest Jiaotong University.

53. Yen, C. L., Chao, S. H., Lin, C. Y. (2011). Field testing of regulatory focus theory. Journal of Applied Social Psychology, 41(6), 1565-1581. DOI 10.1111/j.1559-1816.2011.00766.x.

54. Kennel, V. L. (2012). The effects of group regulatory focus, psychological safety, and communication on the accuracy of team idea evaluation and selection (Doctoral dissertation). University of Nebraska at Omaha.

55. Song, P., Guang, T. (2019). I would speak up to live up to your trust: The role of psychological safety and regulatory focus. Frontiers in Psychology, 10, 2966. DOI 10.3389/fpsyg.2019.02966.

56. Cui, H. J., Yao, F., Jin, X. T., Zhao, T. Y., Smyczek, S. (2021). Effect of regulatory focus on food variety-seeking behavior of Chinese tourists. Journal of Hospitality \& Tourism Research, 2(3), 1-24. 10.1177/ 1096348020988893.

57. Lee, J., Kim, H. R., Yun, S. (2016). Knowledge sharing, psychological safety, and performance: Moderating effect of regulatory focus. Academy of Management Annual Meeting Proceedings, 2016(1), 1-24. DOI 10.5465/ ambpp.2016.14960abstract.

58. Salari, R., Backman, A. (2016). Direct marketing of parenting programs: Comparing a promotion-focused and a prevention-focused strategy. The European Journal of Public Health, 27(3), 489-494. DOI 10.1093/eurpub/ ckw149. 
59. Li, X. H., Li, M., Fu, J., Ullah, A. (2019). Leader humility and employee voice: The role of employees' regulatory focus and voice-role conception. Social Behavior and Personality: an International Journal, 47(6), 1-12. DOI 10.2224/sbp.7811.

60. Porath, C. L., Pearson, C. M. (2012). Emotional and behavioral responses to workplace incivility and the impact of hierarchical status. Journal of Applied Social Psychology, 42(1), 326-357. DOI 10.1111/j.1559-1816.2012.01020.x.

61. Xie, J., Huang, Q., Wang, H., Shen, M. (2018). Who favors support more in workplace gossip: The joint roles of external social support and gender. Academy of Management Annual Meeting Proceedings, 2018(1), 14249. DOI 10.5465/AMBPP.2018.14249abstract.

62. Zhang, Y., Xu, S., Long, Z., Liu, S. (2018). How family support influences work cynicism and employee silence: The moderating role of gender. Cornell Hospitality Quarterly, 60(5), 249-261. DOI 10.1177/1938965518788526.

63. Hayes, A. (2013). Introduction to mediation, moderation, and conditional process analysis. Journal of Educational Measurement, 51(3), 335-337. DOI 10.1111/jedm.12050.

64. Aiken, L. S., West, S. G. (1991). Multiple regression: Testing and interpreting interactions-institute for social and economic research, pp. 167-168. CA: Sage, Newbury Park.

65. Zhou, A. Y., Liu, X. S., Xu, H. (2019). Gossip fiercer than a tiger: Effect of workplace negative gossip on targeted employees' innovative behavior. Social Behavior and Personality an International Journal, 47(5), 1-11. DOI 10.2224/sbp.5727.

66. Ye, Y. J., Zhu, H., Deng, X. C.,Mu, Z. R. (2019). Negative workplace gossip and service outcomes: An explanation from social identity theory. International Journal of Hospitality Management, 82, 159-168. DOI 10.1016/j. ijhm.2019.04.020.

67. Yao, Z., Luo, J., Zhang, X. (2020). Gossip is a fearful thing: The impact of negative workplace gossip on knowledge hiding. Journal of Knowledge Management, 24(7), 1755-1775, DOI 10.1108/JKM-04-2020-0264.

68. Pacheco, D. C., Caldeira, S. N., Moniz, A. (2015). Silence in organizations and psychological safety: A literature review. European Scientific Journal, 5(7), 293-308.

69. Liu, X., Yang, S., Yao, Z. (2020). Silent counterattack: The impact of workplace bullying on employee silence. Frontiers in Psychology, 11, 572236. DOI 10.3389/fpsyg.2020.572236.

70. Li, X. Y., Zhang, Y. L., Gong, Z. X. (2018). Abusive management motivates employee ingratiation: The mediating role of self-esteem and the moderating role of moderating focus. Journal of Business Economics, 326(12), 43-53. DOI 10.14134/j.cnki.cn33-1336/f.2018.12.004.

71. Ribeiro, V. E., Blakeley, J. A. (1995). The proactive management of rumor and gossip. Journal of Nursing Administration, 25(6), 43-50. DOI 10.1097/00005110-199506000-00010. 